\title{
The effect of Trichoderma isolates, from family mushroom growing farms, on the yield of four Agaricus bisporus (Lange) Imbach strains
}

\author{
Romuald Górski ${ }^{1}$, Krzysztof Sobieralski2*, Marek Siwulski², \\ Barbara Fraszczak², Iwona Sas-Golak²

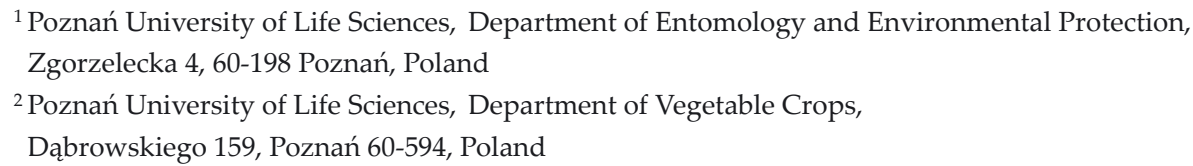

Received: January 13, 2014

Accepted: March 5, 2014

\begin{abstract}
The effect of different Trichoderma species on the yield of Agaricus bisporus strains was investigated in this study. For the first time, the effect of different Trichoderma species on the yield of Agaricus bisporus strains was determined under fully controlled conditions. Four button mushroom strains were used: Somycel 53, Somycel 11, Amycel 2200, and Polmycel 31. The cultivation substrate was inoculated with the following Trichoderma species: T. aggressivum f. europaeum, T. atroviride, T. hamatum, T. harzianum, T. inhamatum, T. koningii, and T. longibrachiatum. Except for T. atroviride, all the Trichoderma isolates reduced the yield of the button mushroom strains.
\end{abstract}

Key words: button mushroom, green moulds, inoculation, substrate, yield

\section{Introduction}

The green moulds of the Trichoderma genus are one of the most dynamic fungal groups in the world. They are perfectly adapted to decompose organic materials, and are especially adept at decomposing cellulose. They also have a set of enzymes which are capable of decomposing very complicated compounds. The conditions in the cultivation chamber, i.e. abundance of organic matter, high temperature, and humidity, provide the perfect conditions for their growth and development (Savoie et al. 2001).

Infestation with green moulds causes considerable losses on mushroom farms. So far no effective methods of eradicating Trichoderma fungi from these farms have been developed. The following Trichoderma species found on mushroom growing farms have been described in detail: T. harzianum, T. viride, T. aureoviride, T. koningi, T. hamatum, T. piluriferum, T. psedokoningii, T. longibrachiatum, T. inhamatum, T. croceum, T. stricipile, T. atroviride, T. cf. virens, and T. parceramosum. Among the above mentioned species, the greatest losses in button mushroom production are caused by T. harzianum, found in four strains or biotypes (Sharma et al. 1999; Fletcher and Gaze 2008).

The aggressive strains of the T. harzianum species were identified as Th2 and Th4. The unaggressive strains of the species were identified as Th1 and Th3. At present in reference publications, the aggressive Th2 strain is identified as the T. aggressivum f. europaeum (Th2) species, whereas the Th4 strain is identified as T. aggressivum (Th4). It is found in North America. The aggressive strains of the T. harzianum species, i.e. Th2 and Th4, are distinguished from the morphologically similar strains of T. harzianum and T. atroviride by their growth rate (Seaby 1996).

Many scientific centres all over the world are conducting research on the potential fungi eradication of the Trichoderma genus, from button mushroom and oyster mushroom farms. Issues related with the development, identification, classification, and physiology of the Trichoderma fungi in mushroom growing, are being investigated at the biological, phytopathological, and molecular levels, usually applying the latest analytical and computer techniques (Seaby 1996; Chen et al. 1999; Samuels et al. 2002; Savoie and Mata 2003).

In recent years, Trichoderma strains have been characterised on the basis of: the growth rate of the pathogen's mycelium at different temperatures and on different culture media, their ability to stain the media, and colony odour. Apart from that, spore and shape were analysed by optical and electron microscopy. The size, shape, and distribution of spore clusters were also investigated (Seaby 1996; Williams et al. 2003).

\section{Materials and Methods}

Four strains of button mushroom (Agaricus bisporus) were used in the experiment: Somycel 53 and Somycel 11, grown in Poland in the 1960s and 1970s, as well as Amycel 
Table 1. Origin of Trichoderma sp. isolates derived from Polish mushroom farms

\begin{tabular}{llcccc}
\hline No. & \multicolumn{1}{c}{$\begin{array}{c}\text { Trichoderma } \\
\text { species }\end{array}$} & $\begin{array}{c}\text { Isolate } \\
\text { symbol }\end{array}$ & $\begin{array}{c}\text { Year of isolate } \\
\text { collection }\end{array}$ & Place & $\begin{array}{c}\text { Source } \\
\text { of isolate }\end{array}$ \\
\hline 1 & T. aggresivum f. europaeum & T. agg. $7 / 19$ & 2009 & Kłoda near Leszno & substrate \\
2 & T. atroviride & T. at. $11 / 2$ & 2007 & Skierniewice & casing soil \\
3 & T. hamatum & T. ham. $20 / 3$ & 2009 & Poznan & substrate \\
4 & T. harzianum & T. har. $4 / 11$ & 2008 & Poznan & casing soil \\
5 & T. inhamatum & T. inh $23 / 2$ & 2009 & Skierniewice & casing soil \\
6 & T. koningii & T. kon. $16 / 4$ & 2008 & Gniezno & substrate \\
7 & T. longibrachiatum & T. lon $7 / 2$ & 2009 & Poznań & substrate \\
\hline
\end{tabular}

2200 and Polmycel 31, grown in Poland in the 2000s. The strains came from the collection of cultivated and medicinal mushrooms of the Department of Vegetable Crops, the Poznań University of Life Sciences, Poland. Isolates of different fungal species from the Trichoderma genus used in the experiments came from the same collection (Table 1).

The cultivation experiment was conducted on the phase II substrate from a composting facility. The cultivation was located in an air-conditioned chamber in containers of $38 \times$ $\times 30 \times 18 \mathrm{~cm}$. Incubation was conducted at a temperature of $25^{\circ} \mathrm{C}$ for 12 days; the relative humidity was $85-90 \%$. Next, when the substrate was overgrown with mycelium, it was inoculated with the granular mycelium of the investigated Trichoderma isolates. Each time, $20 \mathrm{~g}$ of the mycelium was introduced to the cultivation container and mixed with the substrate. Incubation was continued at a temperature of $25^{\circ} \mathrm{C}$; the relative humidity was $85-90 \%$. The substrate overgrown with mycelium was covered with a 5-cm layer of high-moor peat neutralised with calcium carbonate to a $\mathrm{pH}$ of 7.5. Fruiting bodies were collected for seven weeks and the yield was calculated per $1 \mathrm{~m}^{2}$ of the cultivated area. Each time, the substrate which was not inoculated with a Trichoderma isolate, was used as the control.

The experiment was performed in four replications in two cultivation cycles. The experimental method is described in detail in Sobieralski et al. (2012).

\section{Results}

In most cases infestation of the substrate with different fungal isolates of the Trichoderma genus caused a considerable yield reduction. The greatest decrease in yield was caused by substrate infestation with the isolate of T. aggresivum $\mathrm{f}$. europaeum (Fig. 1). In all of the cases, a very high yield reduction could be observed. In the Amycel 2200 strain, the yield from the non-infested control was $15.6 \mathrm{~kg} / \mathrm{m}^{2}$, whereas it was as low as $1.5 \mathrm{~kg} / \mathrm{m}^{2}$ when the strain was infested with the aforementioned isolate. Substrate infestation with the T. at. 11/2 isolate of T. atroviride did not result in a statistically significant yield reduction of any of the strains (Fig. 2). Substrate infestation with the T. ham. 20/3 isolate caused a yield reduction in three strains, except for Amycel 2200, where the yield was similar both on the infested and non-infested substrate (Fig. 3). Substrate infestation with the other isolates, i.e. T. har. 4/11 of T. harzianum, T. inh. 23/2 of T. inhamatum, T. kon. 16/4 of T. koningii and T. lon. 7/2 of T. longibrachiatum, caused a statistically significant yield reduction (Fig. 4-7).

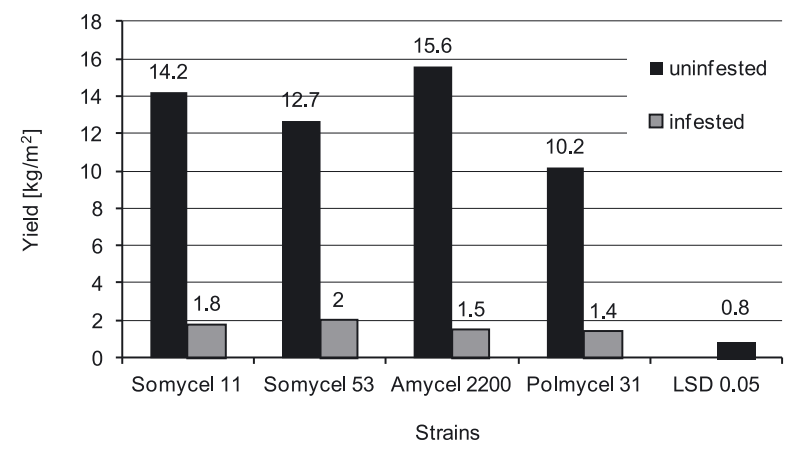

Fig. 1. Yield of a cultivated strain A. bisporus infested with the T. agg. 7/19 isolate of T. aggressivum

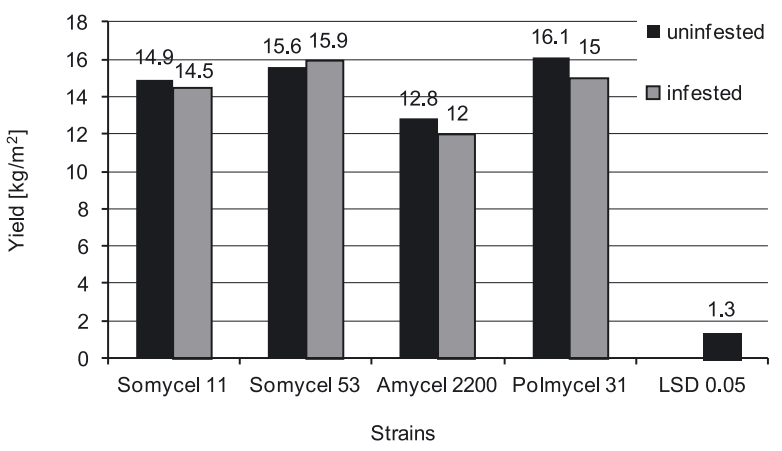

Fig. 2. Yield of a cultivated strain A. bisporus infested with the T. at. 11/2 isolate of T. atroviride

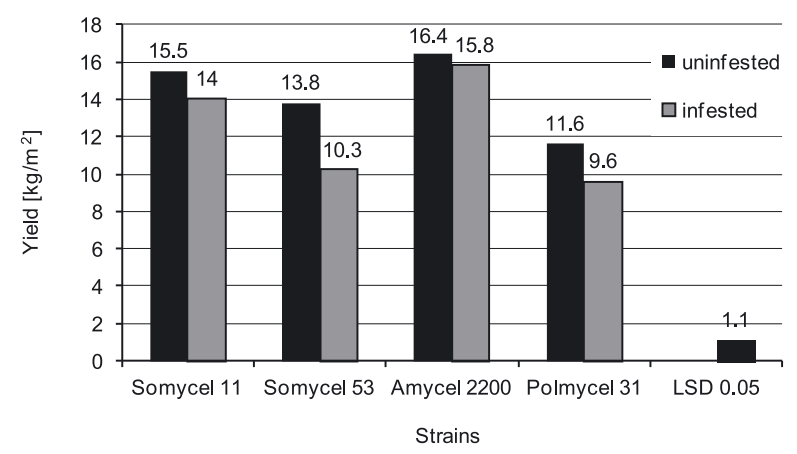

Fig. 3. Yield of a cultivated strain A. bisporus infested with the T. ham. 20/3 isolate of T. hamatum 


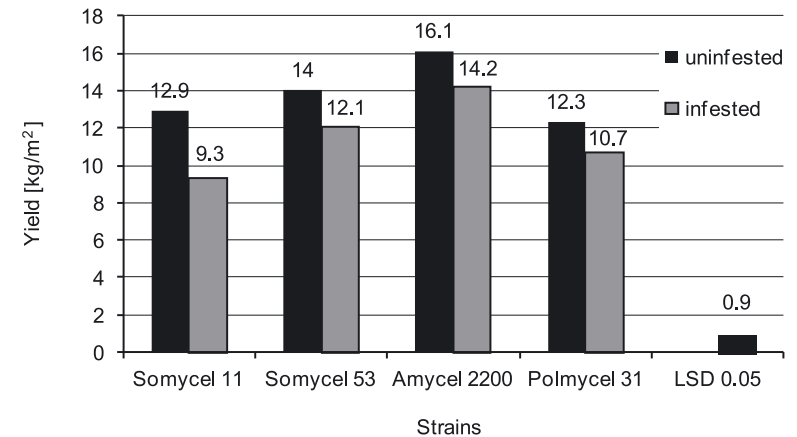

Fig. 4. Yield of a cultivated strain A. bisporus infested with the T. har. 4/11 isolate of T. harzianum

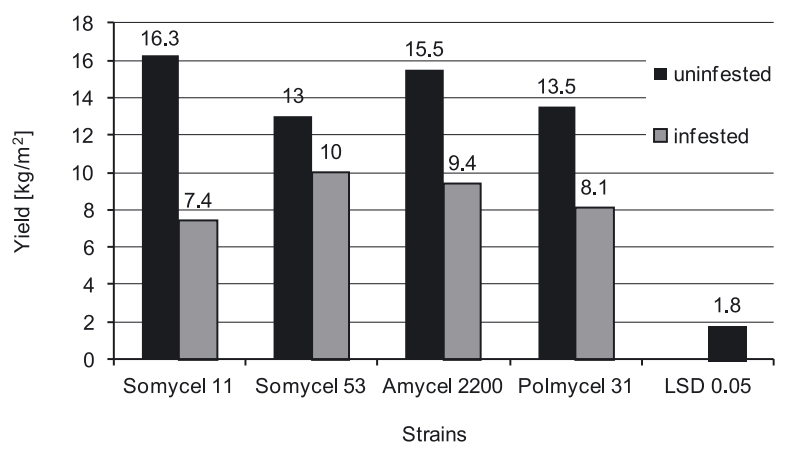

Fig. 5. Yield of a cultivated strain A. bisporus infested with the T. inh. 23/2 isolate of T. inhamatum

\section{Discussion}

Our study results partly confirmed the results reported by other authors. According to many researchers, a wide range of fungal species of the Trichoderma genus may be found in the substrate for button mushroom cultivation. These fungi do not have any significant effect on the button mushroom yield. Pathogenicity of: T. viride, T. aureoviride, T. pseudokoningii, and T. hamatum is relatively low (Fletcher and Gaze 2008). In contrast, strain Th2, which is now identified as Trichoderma aggressivum f. europaeum, is very aggressive (Seaby 1996; Williams et al. 2003).

Our study showed that the yield of the button mushroom strains was very strongly limited by the T. aggressivum f. europaeum isolate T. agg. 7/19. These findings are in agreement with the findings by Seaby (1996) and Williams et al. (2003). A study conducted by those authors showed that a wide range of Trichoderma isolates which are considered to be less aggressive, may cause a statistically significant yield reduction in different button mushroom strains.

Of the isolates of different investigated Trichoderma species, only the T. atroviride isolate T. at 11/2 caused no statistically significant yield reduction in the four button mushroom strains under analysis. The T. ham. 20/3 isolate of T. hamatum reduced yields in three of the analysed strains, but it did not have a significant effect on the yield of Amycel 2200. Our findings largely confirm the earlier findings of other authors who showed diversification in the yield of button mushroom strains grown on a substrate infested with different T. aggressivum f. europaeum isolates. Brown button mushroom strains responded

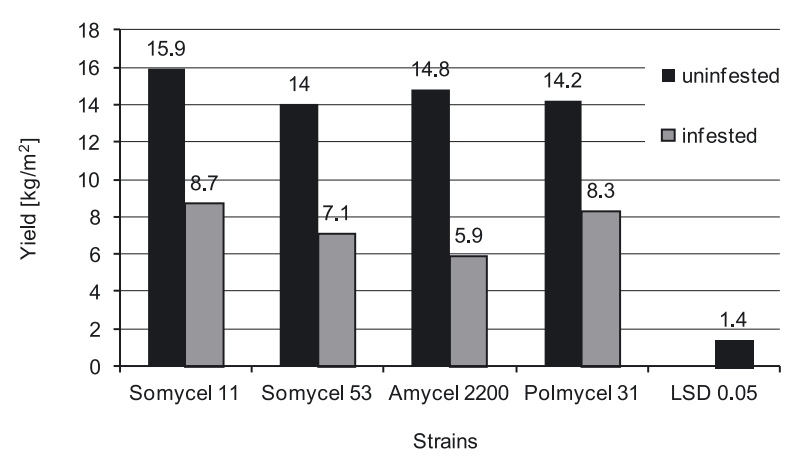

Fig. 6. Yield of a cultivated strain $A$. bisporus infested with the T. kon 16/4 isolate of T. koningii

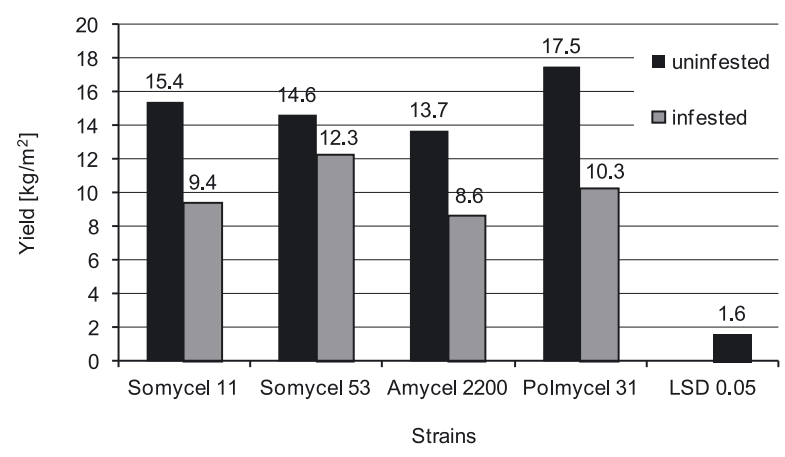

Fig. 7. Yield of a cultivated strain $A$. bisporus infested with the T. lon. $7 / 2$ isolate of $T$. longibrachiatum

with a considerably lower yield than white strains (Sobieralski et al. 2009). Other studies showed that T. aggressivum $\mathrm{f}$. europaeum isolates always caused a reduction in the number of primordia, and a considerable yield decrease (Sobieralski et al. 2010).

There was considerable diversification in the strains under investigation, as they were grown in different decades in Poland. Our study indicated that in spite of considerable diversification, the responses of the strains were very similar. All of the strains under investigation responded with a very high yield reduction when infested with the T. agg. 7/19 isolate of T. aggressivum f. europaeum species. The response to all the other fungal isolates of the Trichoderma genus was very similar. Earlier studies showed diversified yields of the Agaricus bisporus strains grown in natural sites on a substrate infested with different T. aggressivum f. europaeum strains. The yield decrease ranged from $22.7 \%$ to $75 \%$ (Sobieralski et al. 2010).

To sum up, the findings of the study show that most fungal isolates of the Trichoderma genus reduced yields of the button mushroom strains to varying degrees. Only the T. at. 11/2 isolate of the T. atroviride species did not result in a statistically significant yield reduction in any of the four button mushroom strains.

\section{Acknowledgements}

This work was financially supported with funds used for science in the years 2009-2012, as research project No. NN310 089037. 


\section{References}

Chen X., Romaine C.P., Tan Q., Schlagnhauter B., Ospina-Giraldo M.D., Royse D.J., Huff D.R. 1999. PCR-based genotyping of epidemic and preepidemic Trichoderma isolates associated with green mould of Agaricus bisporus. Appl. Environ. Microbiol. 65 (6): 2674-2678.

Fletcher J.T., Gaze R.H. 2008. Mushroom Pest and Disease Control. Manson Publishing Ltd, London, 192 pp.

Samuels G.J., Dodd S.L., Gams W., Castlebury L.A., Petrini O. 2002. Trichoderma species associated with the green mould epidemic of commercially grown Agaricus bisporus. Mycology 94 (1): 146-170.

Savoie J-M., Iapicco R. Largeteau-Mamoun M. 2001. Factors influencing the competitive saprophytic ability of Trichoderma harzianum Th2 in mushroom compost. Mycol. Res. 105 (11): 1348-1356.

Savoie J.M., Mata G. 2003. Trichoderma harzianum metabolites pre-adapt mushrooms to Trichoderma aggressivum antagonism. Mycology 95 (2): 191-199.

Seaby D.A. 1996. Differentiation of Trichoderma taxa associated with mushroom production. Plant Pathol. 45 (5): 905-912.
Sharma H.S.S., Kilpatrick M., Ward F., Lyynos G., Burns L. 1999. Colonization of phase II compost by biotypes of Trichoderma harzianum and their effect on mushroom yield and quality. Appl. Microbiol. Biotech. 51 (5): 572-578.

Sobieralski K., Siwulski M., Frużyńska-Jóźwiak D., Górski R. 2009. Impact of Trichoderma aggressivum $\mathrm{f}$. europaeum Th2 on the yielding of Agaricus bisporus. Phytopathologia 53: 5-10. Sobieralski K., Siwulski M., Jasińska A., Frużyńska-Jóźwiak D., Sas-Golak I., Szymański J. 2010. Impact of infections with Trichoderma agressioum $\mathrm{f}$. europaeum isolates on the yielding of some wild strains of Agaricus bitorquis (Quel.) Sacc. from different regions of Poland. Phytopathologia 58: 5-11.

Sobieralski K., Siwulski M., Błaszczyk L., Frużyńska-Jóźwiak D. Lisiecka J. 2012. The effect of infestation with isolates of Trichoderma sp. on mycelium growth and yielding in singlespore heterokaryotic cultures of Agaricus bisporus (Lange) Imbach. Acta Sci. Pol., Hortorum Cultus 11 (6): 47-57.

Williams J., Clarkson J.M., Mils P.R., Cooper R.M. 2003. Saprotrophic and mycoparasitic components of aggressiveness of Trichoderma harzianum groups toward the commercial mushroom Agaricus bisporus. Appl. Environm. Microbiol. 69 (7): 4192-4199. 